\title{
HIV-1 induces in vivo platelet activation by enhancing platelet NOX2 activity
}

\section{Q4 Daniele Pastori ${ }^{a}$, Antonella Esposito ${ }^{b}$, Roberto Carnevale ${ }^{a, c}$, Simona Bartimoccia ${ }^{a}$, Marta Novo ${ }^{a}$, Alessandra Fantauzzi ${ }^{\text {b }}$, Francesco Di Campli ${ }^{b}$, Pasquale Pignatelli ${ }^{a, *}$, Francesco Violi ${ }^{a}$, Ivano Mezzaroma}

\footnotetext{
a Department of Internal Medicine and Medical Specialties, "Sapienza" University of Rome, Rome, Italy

b Department of Clinical Medicine, "Sapienza" University of Rome, Rome, Italy

'Department of Medical-Surgical Sciences and Biotechnologies, Sapienza University of Rome, Latina, Italy
}

Accepted 9 January 2015

Available online

\section{KEYWORDS \\ HIV-1; \\ Platelet activation; \\ NOX; \\ Isoprostanes}

\begin{abstract}
Summary Objectives: HIV-1 patients show increased platelet activation, but the mechanisms involved are not completely clarified. We speculated that HIV-1 might induce in vivo platelet activation by enhancing platelet NOX2-related oxidative stress.

Methods: We measured soluble CD40 Ligand (sCD40L), a systemic marker of platelet activation, in 36 HIV-1 patients under effective combined antiretroviral therapy (CART) and in 10 naïve HIV-1 subjects. As control, 20 healthy subjects (HS) were included. Platelet oxidative stress was measured by platelet NOX2-derived peptide (sNOX2-dp), p47 ${ }^{\text {phox }}$ translocation to platelet membrane and platelet prostaglandin $\mathrm{F}_{2 \alpha}\left(8\right.$-iso- $\left.\mathrm{PGF}_{2 \alpha}\right)$.

Results: sCD40L was increased both in HIV-1 naïve and CART patients compared to HS $(\mathrm{p}<0.001)$. Platelet sNOX2-dp and 8-iso-PGF $2 \alpha$ were significantly higher in HIV-1 naïve subjects compared to those on CART and to HS, and both were mutually correlated $(R=0.734$, $\mathrm{p}<0.001)$. A stepwise multivariable linear regression analysis showed that platelet sNOX2dp $(\beta: 0.803, p<0.001)$, HIV-1 infection $(\beta: 0.146, p=0.014)$ and age $(\beta: 0.166$, $\mathrm{p}=0.001$ ) were independently associated to SCD40L levels.

Conclusions: HIV-1 infection is associated with increased platelet oxidative stress, which was
\end{abstract}


related to the activation of NOX2. The independent association between platelet NOX2 activation and plasma levels of SCD40L suggest that in vivo platelet activation may be dependent upon platelet oxidative stress.

(c) 2015 Published by Elsevier Ltd on behalf of The British Infection Association.

\section{Q1 Introduction}

The use of effective combined antiretroviral therapy (cART) have progressively lengthened the survival of patients with Human Immunodeficiency Virus type 1 (HIV-1) infection and dramatically reduced the disease progression to full-blown Acquired Immunodeficiency Syndrome (AIDS). ${ }^{1}$ Prolonged life expectancy revealed a previously unrecognized risk of developing cardiovascular (CV) diseases in HIV-1 patients, with an accelerated atherosclerosis, ${ }^{2,3}$ increased coronary heart disease and atherosclerotic plaque vulnerability. ${ }^{4,5}$ Ischemic complications may include not only coronary, but also cerebrovascular disease, affecting intracranial vessels and leading to progressive neurological and cognitive impairment. ${ }^{6,7}$

Platelet activation play a crucial role on the onset of atherosclerotic complications, ${ }^{8}$ and recent evidences suggest that patients with HIV-1 infection disclose an enhanced platelet activation. ${ }^{9}$

Nicotinamide adenine dinucleotide phosphate (NADPH) oxidase is a key enzyme involved in reactive oxygen species (ROS) production. ${ }^{10} \mathrm{NADPH}$ oxidase, which was well defined in phagocytic cells, is composed of plasma membranebound subunits (gp91 $1^{\text {phox }} /$ NOX2 and $\mathrm{p} 22^{\text {phox }}$ ) and several cytosolic subunits. ${ }^{11}$ Assembly of the cytosolic subunits with NOX2 leads to enzyme activation and ROS production. Upon activation, NOX2 releases a soluble peptide (sNOX2$\mathrm{dp}$ ), which is a direct expression of the enzyme activation. $^{12}$

NOX2 was identified in platelets ${ }^{13}$ and its activation was recognized to be a fundamental step in the formation of platelet prostaglandin $\mathrm{F}_{2 \alpha}$ (8-iso- $\mathrm{PGF}_{2 \alpha}$ ) in response to cell agonists, arachidonic acid in particular. ${ }^{14,15}$ NOX2 activation is also a critical step for the release of prothrombotic molecules such as soluble CD4OL (sCD40L), ${ }^{10,13}$ indicating that NOX2 may be implicated on in vivo platelet activation. Indeed, SCD40L has been proposed as a reliable marker of platelet activation. ${ }^{16}$

Therefore, we speculated that NOX2 activity is upregulated in platelets from HIV-1 patients, so contributing to in vivo platelet activation.

Thus, aim of our study is to investigate the behavior of platelet activation and its interaction with platelet NOX2 in HIV-patients.

\section{Materials and methods}

\section{Patients}

Forty-six HIV-1 infected patients were enrolled. Subjects were followed in an outpatient basis at the Department of Clinical Medicine, "Sapienza" University of Rome. Thirty-six patients were included according to the following criteria: diagnosis of HIV-1 infection at any stage; effective CART with a viral load $<37$ copies/mL from at least 12 months; age $>18$ years; absence of severe obesity, arterial hypertension, diabetes mellitus, and dyslipidemia. Patients with an active opportunistic infection were excluded.

HIV-1 patients were treated with CART according to current guidelines. ${ }^{17}$ Medication compliance was assessed with regular drug refill.

Another group of 10 naive HIV-1 patients with similar demographic and clinical characteristics was enrolled. As control, 20 healthy subjects (HS) from the same geographic area matched for sex and age were included.

The study was approved by local ethic committee and conducted according to the principles of the Declaration of Helsinki. ${ }^{18}$ All enrolled subjects gave their written informed consent.

\section{Platelet preparation}

Blood samples were obtained after a 12 -h fast between 8.00 and 9.00 a.m. from subjects underwent routine biochemical analysis including total cholesterol and glucose. Samples, obtained from healthy subjects after supine rest for at least $10 \mathrm{~min}$, were taken into tubes with $3.8 \%$ sodium citrate. To acquire platelet-rich plasma (PRP), samples were centrifuged for $15 \mathrm{~min}$ at $180 \mathrm{~g}$. In order to avoid leukocyte contamination, only the top $75 \%$ of the PRP was collected according to Pignatelli et al. ${ }^{12}$ Platelet pellets were obtained by double centrifugation $(5 \mathrm{~min}, 300 \mathrm{~g})$ of PRPs. Acid/citrate/dextrose (ACD) (1:7 $\mathrm{v} / \mathrm{v}$ ) was added to avoid platelet activation during processing. Samples were suspended in HEPES buffer in presence of $0.1 \%$ albumin, $\mathrm{pH} 7.35$. Platelet concentration in samples used for in vitro experiments was adjusted at $2 \times 10^{5}$ platelets $/ \mathrm{mL}$. Cells were activated with Arachidonic Acid $(0.5 \mathrm{mM})$ for $10 \mathrm{~min}$ at $37^{\circ} \mathrm{C}$, separated from the supernatant by centrifugation $(5 \mathrm{~min}, 300 \mathrm{~g})$ and the two fractions, cells and supernatants, were stored at $-80{ }^{\circ} \mathrm{C}$ until analysis. All materials used were from Sigma Aldrich unless otherwise specified.

\section{Plasma soluble CD40L}

Plasma levels of soluble CD40L (sCD40L) were measured with a commercial immunoassay (Tema Ricerca, Bologna, Italy). Values were expressed as $\mathrm{ng} / \mathrm{ml} / 2 \times 10^{5}$ platelets. Intra-assay and inter-assay coefficients of variation were $5 \%$ and $7 \%$ respectively. The detection limits is $0.16 \mathrm{ng} / \mathrm{ml}$.

\section{Analysis of platelet sNOX2-dp}

Extracellular levels of soluble NOX2-derived peptide (sNOX2-dp), were detected by an ELISA method as previously described by Pignatelli et al. ${ }^{12}$ in the supernatant of 
platelet suspension. The peptide was recognized by the specific monoclonal antibody against the amino acidic sequence of the extra membrane portion of NOX2 (catalytic core of NADPH oxidase), which was released in the medium upon platelet activation with $\mathrm{AA} .{ }^{12}$ Values were expressed as $\mathrm{pg} / \mathrm{ml} / 2 \times 10^{5}$ platelets; intra-assay and inter-assay coefficients of variation were $5.2 \%$ and $6 \%$, respectively.

\section{Platelet isoprostanes}

Prostaglandin $\mathrm{F}_{2 \alpha}$ (8-iso- $\mathrm{PGF}_{2 \alpha}$ ) was measured by a previously described and validated enzyme immunoassay method $^{19,20}$ in the supernatant of platelet suspension. 8iso-PGF $2 \alpha$ values were expressed pmol/L/2 $\times 10^{5}$ platelets. Intra-assay and inter-assay coefficients of variation were $4.4 \%$ and $8.8 \%$, respectively.

\section{Membrane and cytoplasmic protein extraction}

Briefly, the extraction of membrane and cytoplasmic proteins was performed by using the Proteo JETTM Membrane Protein Extraction Kit (Fermentas International Inc, Maryland, USA) as reported by Fortuño et al. ${ }^{21}$

\section{Western blot analysis of $\mathrm{p} 47^{\text {phox }}$}

Platelets from patients who were evaluated for $\mathrm{p} 47^{\text {phox }}$ translocation were analyzed immediately after the blood sample collection. Platelets were suspended in a $2 \times$ Lysis

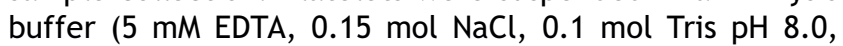
$1 \%$ triton and protease inhibitor cocktail). Equal amounts of protein ( $30 \mu \mathrm{g} /$ lane) estimated by Bradford assay were solubilized in a $2 \times$ Laemmli buffer containing 2mercaptoethanol and loaded in a denaturing SDS/10\% polyacrylamide gel. Western blot analysis was performed with monoclonal anti-p47 ${ }^{\text {phox }}$ (Santa Cruz Biotechnology, Dallas, USA) $(1 \mu \mathrm{g} / \mathrm{ml})$ incubated overnight at $4{ }^{\circ} \mathrm{C}$. Immune complexes were detected by enhanced chemiluminescence. The developed spots were calculated by densitometric analysis on a NIHimage $1.62 \mathrm{f}$ analyzer and the values were expressed in arbitrary unit (AU).

In particular, we removed from the densitometric analysis the aspecific spot, and the values were expressed as the ratio between the absolute values of the membranes spots divided to absolute values of the corresponding cytosolic spots (Densitometric Analysis of Membrane Spots - Densitometric Analysis of Aspecific Spots/Densitometric Analysis of Cytosol Spots - Densitometric Analysis of Aspecific Spots).

\section{Statistical analysis}

Categorical variables were reported as counts (percentages) and continuous variables as means \pm standard deviation (SD) or median and interquartile range (IQR) unless otherwise indicated. Independence of categorical variables was tested by $\chi^{2}$ test. Normal distribution of parameters was assessed by Kolmogorov-Smirnov test.

Student unpaired $\mathrm{t}$ test and Pearson product-moment correlation analysis were used for normally distributed continuous variables. Group comparisons were performed using analysis of variance (ANOVA). Appropriate nonparametric tests (Mann-Whitney $U$ test, Kruskal-Wallis test, Spearman rank correlation test) were employed for all the other variables. Stepwise multivariable linear regression analysis was used to assess factors influencing sCD40L. Only $\mathrm{p}$ values lower than 0.05 were considered as statistically significant. All tests were two-tailed and analyses were performed using computer software packages (SPSS-18.0, SPSS Inc.).

\section{Sample size}

On the basis of the results from a previous work on healthy subjects, ${ }^{22}$ we calculated that a minimum of 10 patients per group were required to have a $90 \%$ chance of detecting, as significant at the $5 \%$ level, a difference for platelet NOX2 between groups of $6 \mathrm{pg} / \mathrm{ml}$ with SD $=4 \mathrm{pg} / \mathrm{ml}$.

\section{Results}

\section{Clinical and biochemical characteristics}

Table 1 reports clinical characteristics of healthy subjects (HS), HIV-1 naïve subjects, and HIV-1 subjects on CART. No differences on age, systolic and diastolic blood pressure, BMI, fasting blood glucose, total cholesterol, platelet count and smoking were present among groups. None of patients or controls was receiving a treatment with antiplatelet drugs or statins at baseline.

\section{Antiretroviral agents}

HIV-1 patients on CART were receiving non-nucleoside reverse transcriptase inhibitor (NNRTI) - or protease inhibitor (PI)-based regimens (23 and 13 patients, respectively), both in association with a nucleos(t)ide reverse transcriptase inhibitor (NRTI) fixed-dose combination (lamivudine/ zidovudine or emtricitabine/tenofovir difumarate). Median length of CART was 136.2 [84.4-204.1] months, and nadir of CD4 + T cells was $269.9 \pm 131.3$ cells $/ \mu \mathrm{l}$. There was no difference in the length of cART between the group with NNRTI-based and PI-based CART (124.8 [91.6-183.3] vs. 164.0 [28.4-214.9] months, $p=0.829)$. HIV-1 patients receiving CART had higher values of CD4+ T lymphocytes compared to HIV-1 naïve subjects (CD4\% $34.0 \pm 11.9$ vs. $23.5 \pm 6.3, \mathrm{p}=0.011 ; \mathrm{CD} 4+\mathrm{T}$ absolute numbers $786.9 \pm 354.6$ vs. $507.8 \pm 390.9$ cells $/ \mu \mathrm{l}, \mathrm{p}=0.037)$. Viral load was undetectable in all HIV-1 cART treated patients, whereas among HIV-1 naïve subjects, median value of viral load was 1711.0 copies/ml [IQR 129.2-8191.5].

\section{Platelet activation and oxidative stress}

\section{Platelet activation}

After stimulation with AA, HIV-1 subjects showed increased values of SCD40L $(21.1 \pm 5.8$ vs. $12.6 \pm 3.3 \mathrm{ng} / \mathrm{ml}$, $\mathrm{p}<0.001$ ) compared to HS (Fig. 1). When we analyzed separately HIV-1 naive subjects and HIV-1 subjects on CART, we found an increased level of SCD40L in naïve HIV1 infected group $(25.9 \pm 4.12 \mathrm{ng} / \mathrm{ml})$, compared to the CART one (19.7 $\pm 5.57 \mathrm{ng} / \mathrm{ml}, \mathrm{p}=0.002)$ (Fig. 1). 
Table 1 Demographic characteristics of seronegative and seropositive subjects.

\begin{tabular}{|c|c|c|c|c|}
\hline & HIV-1 negative $(n=20)$ & HIV-1 cART group $(n=36)$ & HIV-1 naïve subjects $(n=10)$ & $p$ value ${ }^{a}$ \\
\hline Age (years) & $37.4 \pm 12.2$ & $42.6 \pm 7.0$ & $43.7 \pm 8.6$ & 0.091 \\
\hline Female (n/\%) & $12(60.0 \%)$ & $11(30.6 \%)$ & $5(50.0 \%)$ & 0.089 \\
\hline High $(\mathrm{cm})$ & $169.4 \pm 10.8$ & $172.9 \pm 8.3$ & $168.8 \pm 7.1$ & 0.263 \\
\hline Weight (kg) & $64.6 \pm 9.9$ & $68.9 \pm 10.5$ & $63.8 \pm 11.5$ & 0.215 \\
\hline Body Mass Index $\left(\mathrm{kg} / \mathrm{m}^{2}\right)$ & $22.6 \pm 3.2$ & $23.1 \pm 2.5$ & $22.2 \pm 3.0$ & 0.659 \\
\hline Fasting blood glucose (mg/dl) & $86.7 \pm 9.0$ & $83.3 \pm 9.2$ & $81.9 \pm 7.7$ & 0.656 \\
\hline Total cholesterol (mg/dl) & $185.1 \pm 17.5$ & $188.1 \pm 51.3$ & $160.7 \pm 44.8$ & 0.133 \\
\hline Platelet count $\left(\times 10^{3} / \mu \mathrm{l}\right)$ & $201.7 \pm 17.6$ & $189.8 \pm 43.1$ & $191.8 \pm 12.9$ & 0.447 \\
\hline Smoking (\%) & 45.0 & 51.4 & 60.0 & 0.736 \\
\hline Systolic blood pressure (mmHg) & $111.4 \pm 9.7$ & $107.9 \pm 7.0$ & $107.5 \pm 5.4$ & 0.232 \\
\hline Diastolic blood pressure $(\mathrm{mmHg})$ & $66.4 \pm 6.3$ & $68.3 \pm 7.3$ & $71.0 \pm 5.7$ & 0.225 \\
\hline
\end{tabular}

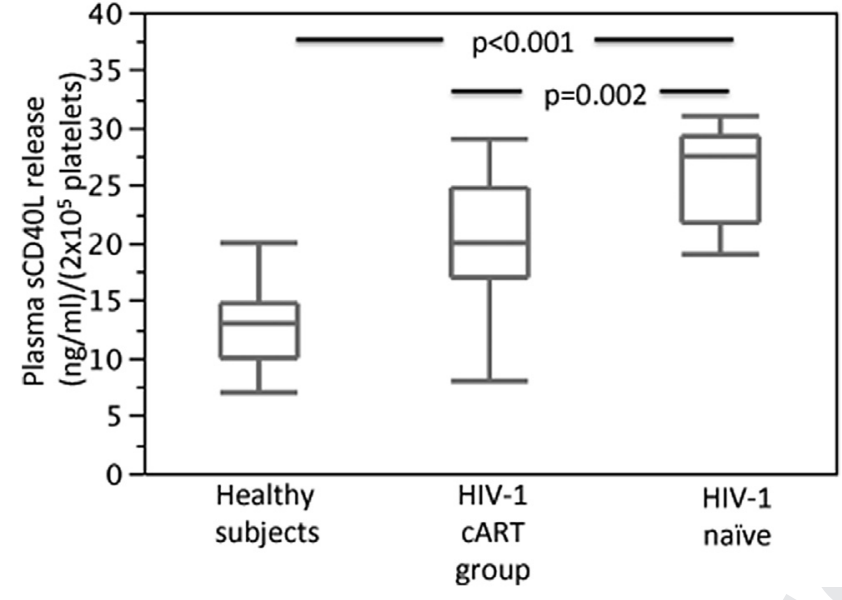

Figure 1 Markers of platelet activation: box and whiskers plots (median, interquartile range) of platelet activation, assessed by plasma sCD40L levels in Healthy Subjects, HIV-1 cART group, and HIV-1 naïve subjects.

\section{Platelet oxidative stress}

Analysis of unstimulated platelets showed that oxidative stress from HIV-1 subjects was higher compared HS. Thus, we found that platelet sNOX2-dp and 8-iso-PGF $2 \alpha$ levels were significantly higher in HIV-1 naïve and HIV-1 CART subjects compared to HS (Fig. 2, Panels $A$ and $B$ ).

After stimulation with AA, platelet sNOX2-dp (23.5 \pm 7.6 vs. $14.8 \pm 3.8 \mathrm{pg} / \mathrm{ml}, \mathrm{p}<0.001$ ), and platelet 8 -iso- $\mathrm{PGF}_{2 \alpha}$ $(148.9 \pm 47.9$ vs. $120.8 \pm 16.8 \mathrm{pmol} / \mathrm{l}, \mathrm{p}=0.001)$ from HIV-1 subjects were higher compared to HS. Moreover, HIV-1 naïve patients disclosed higher platelet sNOX2-dp values $(31.7 \pm 5.4 \mathrm{pg} / \mathrm{ml})$, compared to patients under CART $(21.2 \pm 6.5 \mathrm{pg} / \mathrm{ml} \mathrm{p}<0.001$, Fig. 2 Panel A).

Similarly values of platelet 8 -iso- $\mathrm{PGF}_{2 \alpha}$ were significantly increased in HIV-1 naive patients $(184.3 \pm 28.4 \mathrm{pmol} / \mathrm{l})$ compared to those on CART (139.0 $\pm 47.8 \mathrm{pmol} / \mathrm{l}$, $\mathrm{p}=0.001$, Fig. 2 Panel B).

Platelet 8-iso-PGF $2 \alpha$ and sNOX2-dp levels were highly correlated $(R=0.734, p<0.001)$.

A sub analysis showed a significant difference in platelet oxidative stress between HIV-1 patients treated with PI and those treated with NNRTI (Table 2), both for platelet sNOX2-dp $(\mathrm{p}=0.015)$ and platelet 8-iso-PGF $2 \alpha$ $(p=0.018)$. In addition, patients treated with PI showed increased values of SCD40L, compared to those on NNRTI $(p=0.009)$. Compared to HS, both the PI and NNRTI group showed higher values of sCD40L and sNOX2-dp, whilst
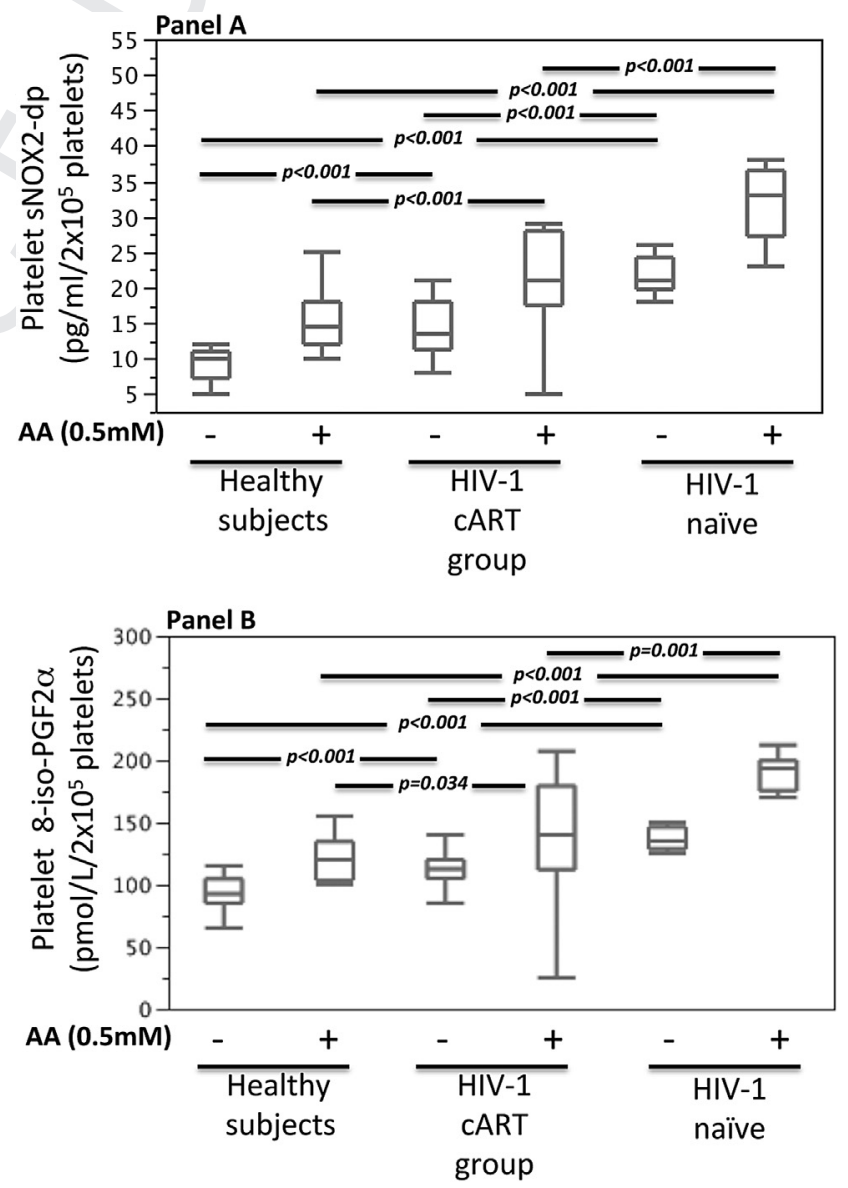

Figure 2 Platelet oxidative stress: box and whiskers plots (median and interquartile range) of platelet sNOX2-dp (Panel A) and platelet 8-iso-PGF2 $\alpha$ (Panel B) levels in Healthy Subjects, HIV-1 cART group, and HIV-1 naïve subjects. 
Table 2 Differences of platelet activation and oxidative stress in AA-stimulated platelets between Healthy Subjects and HIV-1 patients according to the different cART regimens.

\begin{tabular}{|c|c|c|c|c|c|c|}
\hline & \multirow[t]{2}{*}{ Healthy Subjects } & \multirow{2}{*}{$\begin{array}{l}\text { HIV-1 cART } \\
\text { PI-group }\end{array}$} & \multirow[t]{2}{*}{$\mathrm{p}$ value $^{\mathrm{a}}$} & \multirow{2}{*}{$\frac{\text { HIV-1 cART }}{\text { NNRTI-group }}$} & \multirow[t]{2}{*}{$\mathrm{p}$ value $^{\mathrm{a}}$} & \multirow[t]{2}{*}{ PI vs. NNRTI } \\
\hline & & & & & & \\
\hline sCD40L (ng/ml) & $12.6 \pm 3.3$ & $22.5 \pm 3.6$ & $<0.001$ & $18.2 \pm 5.9$ & 0.001 & 0.009 \\
\hline Platelet sNOX2-dp (pg/ml) & $14.8 \pm 3.8$ & $24.2 \pm 4.0$ & $<0.001$ & $19.5 \pm 7.1$ & 0.010 & 0.015 \\
\hline Platelet 8-iso-PGF2 $\alpha(\mathrm{pmol} / \mathrm{l})$ & $120.8 \pm 16.8$ & $162.8 \pm 40.3$ & $<0.001$ & $125.6 \pm 47.1$ & 0.657 & 0.018 \\
\hline
\end{tabular}

CART: combined antiretroviral therapy, PI: protease inhibitor, NNRTI: non-nucleoside reverse transcriptase inhibitor.

a vs. Healthy Subjects.

platelet 8-iso-PGF $2 \alpha$ of patients treated with NNRTI were similar to those of HS (Table 2).

\section{Determinants of SCD40L levels}

Table 3 reports correlations of SCD40L levels with selected variables. We also performed a multivariable linear regression analysis which showed that platelet sNOX2-dp ( $\beta$ : $0.803,95 \% \mathrm{Cl} 0.576-0.763, \mathrm{p}<0.001)$, HIV-1 infection $(\beta$ : $0.146,95 \% \mathrm{Cl} 0.427-3.675, \mathrm{p}=0.014)$ and age $(\beta: 0.166$, $95 \% \mathrm{Cl} 0.046-0.185, \mathrm{p}=0.001)$ were independently associated to SCD40L levels (adjusted $R^{2}: 0.85$ ).

\section{In vitro study}

To further investigate the mechanism underlying NOX2 upregulation, we measured $A A$-induced platelet $p 47^{\text {phox }}$ translocation to cell membrane. We used AA as we previously demonstrated that AA directly induces $\mathrm{p} 47^{\text {phox }}$ activation and translocation to platelet membrane. ${ }^{12}$ We observed that $\mathrm{AA}$ is able to increase the translocation of $\mathrm{p} 47^{\text {phox }}$ to platelet membrane compared to unstimulated platelets, with consequent decrease in the content of the cytosolic fraction (Fig. 3, Panel C).

Western blot analysis showed that membrane levels of p4 $7^{\text {phox }}$ were increased in HIV-1 infected patients compared to $\mathrm{HS}(13.4 \pm 3.7$ vs. $27.0 \pm 10.4 \mathrm{AU}, \mathrm{p}<0.001)$ (Fig. 3, Panels $A$ and $B)$.

Among HIV-1 patients, naïve subjects showed increased value of $\mathrm{p} 47^{\text {phox }}$ compared to those on CART $(41.9 \pm 7.1 \mathrm{vs.}$ $22.9 \pm 6.7 \mathrm{AU}, \mathrm{p}<0.001$ ), and in naïve subjects (vs. cART group), compared to HS (Fig. 3, Panel A). P47phox membrane translocation was significantly associated to NOX2 activation $(\mathrm{R}=0.806, \mathrm{p}<0.001)$.

\section{Discussion}

Results from our study provide evidence that HIV-1 infection is associated with in vivo platelet activation and suggest platelet NOX2 up-regulation as a potential underlying mechanism.

Patients with HIV-1 infection are characterized by accelerated atherosclerosis ${ }^{4}$ and platelet activation is believed to play a major role. ${ }^{9} \mathrm{~A}$ direct interplay between HIV-1 and platelets may be implicated in platelet activation. ${ }^{23}$ Thus, platelets have been shown to possess receptors for viruses, including $\mathrm{HIV}-1,{ }^{24}$ and to be able to internalize HIV-1 acting as phagocytes. ${ }^{25,26}$ Furthermore, a relationship between virus replication and platelet activation has been demonstrated. ${ }^{23,27,28}$ However, the mechanism potentially accounting for platelet activation in HIV-1 subjects it is still undefined.

Previous studies reported that HIV-1 structural and functional proteins may promote NADPH oxidase activation in different cell lines. ${ }^{29-31}$ This finding is of particular interest in the context of platelet function as NADPH oxidase play a relevant role in the process of platelet activation. ${ }^{13}$ Thus, studies from our group demonstrated that platelet express this enzyme, ${ }^{13}$ which, upon activation, is implicated in the mechanism of platelet activation via formation of isoprostanes, a chemically stable eicosanoids with proaggregating properties. ${ }^{14}$ Accordingly, patients with upregulation of the enzyme disclose platelet activation coincidentally with platelet ROS formation and isoprostanes over-production. ${ }^{10}$

In our study, platelets from HIV-1 subjects show enhanced NOX2 activity, as depicted by higher levels of platelet sNOX2-dp. Consistently with this finding platelet 8iso-PGF $2 \alpha$ was higher in HIV-1 patients, especially in HIV-1

Table 3 Correlations of factors associated to SCD40L levels.

\begin{tabular}{llr}
\hline & $\mathrm{R}$ & $\mathrm{P}$ value \\
\hline Presence of HIV-1 infection & 0.604 & $<0.001$ \\
Length of cART & $0.164^{\mathrm{a}}$ & 0.347 \\
Age (years) & 0.296 & 0.016 \\
Body mass index & 0.031 & 0.804 \\
Smoking habit & 0.059 & 0.640 \\
Platelet sNOX2-dp $(\mathrm{pg} / \mathrm{ml})$ & 0.897 & $<0.001$ \\
Platelet 8-iso-PGF2 $\alpha(\mathrm{pmol} / \mathrm{l})$ & 0.707 & $<0.001$ \\
\hline a Spearman correlation. & &
\end{tabular}



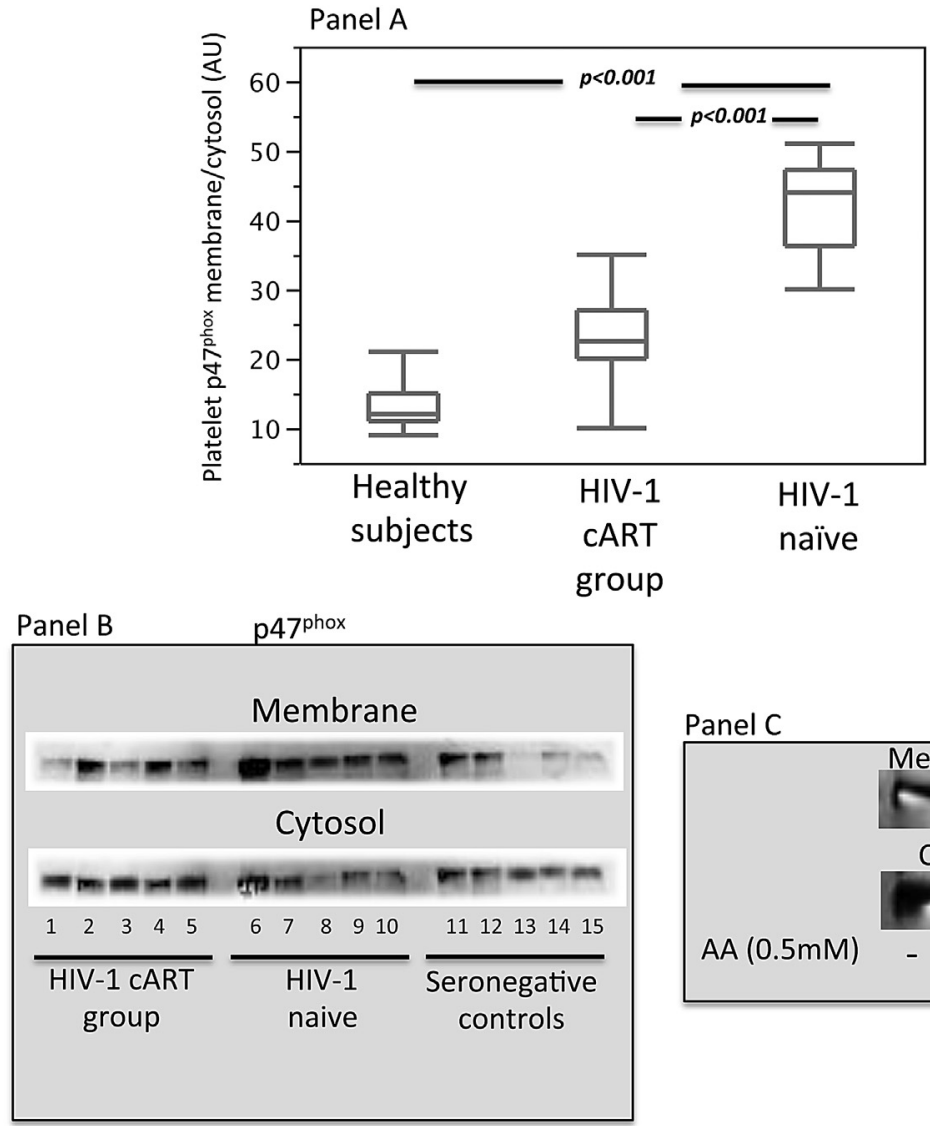

Panel C

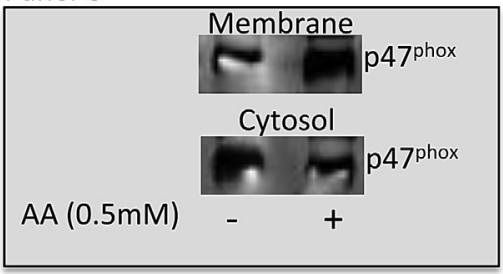

Figure 3 Densitometry evaluation of the membrane p47 ${ }^{\text {phox }}$ content in platelets of Healthy Subjects, HIV-1 cART group and HIV-1 naïve (Panel A). A representative Western blot analysis of the membrane and cytosol p47 ${ }^{\text {phox }}$ content in Healthy Subjects $(n=5)$, HIV-1 CART group $(n=5)$ and HIV-1 naïve $(n=5)$ (Panel B). Western blot analysis of the membrane and cytosol p47 ${ }^{\text {phox }}$ content in HIV-1 naïve $(n=2)$ (Panel C).

naïve subjects, compared to $\mathrm{HS}$. Platelet 8-iso-PGF $2 \alpha$ was highly correlated to sNOX2-dp, confirming, also in this setting, the strong relationship between NOX2 activation and isoprostanes formation. The increased level of isoprostanes is in accordance with previous data reporting increased plasma 8-iso-PGF ${ }_{2 \alpha}$ levels in HIV-1 patients in association with viral replication. ${ }^{32,33}$ Together these data show enhanced NOX2-derived oxidative stress in HIV-1, which is dependent upon the viral replication in the blood. To further substantiate the role of NOX2 in enhancing platelet oxidative stress, we also performed an in vitro study in which we analyzed translocation of the cytosolic $\mathrm{p} 47^{\text {phox }}$ to platelet membrane NOX2. The role of this subunit in NOX2 regulation is evident since subjects with the hereditary deficiency of $\mathrm{p} 47^{\text {phox }}$ showed lower sNOX2-dp level. ${ }^{34} \mathrm{HIV}-1$ patients showed significant increase of membrane translocation of the $\mathrm{p} 47^{\text {phox }}$ in association with enhanced sNOX2dp levels. Furthermore, p47 ${ }^{\text {phox }}$ was more expressed in HIV-1 naïve subjects compared to those receiving CART suggesting a role for viral replication in favoring platelet NOX2 activation.

The results so far reported may provide a mechanistic insight into the increase of in vivo platelet activation detected in HIV-1 patients. Thus, plasma SCD40L, an established marker of platelet activation ${ }^{35}$ was more elevated in HIV-1 subjects compared to HS and significantly correlated with NOX2 regulation, indicating a role for NOX2-derived oxidative stress in eliciting in vivo platelet activation.

Another important finding of our study is that, despite being on effective CART, HIV-1 patients still showed an increased platelet oxidative stress. This was demonstrated by the residual significant difference, in platelet sNOX2-dp and 8 -iso-PGF $F_{2 \alpha}$, between HIV-1 subjects under CART and seronegative subjects. This result may be attributable to the persistence of a minimal residual viral load, responsible for the persistent immune activation and chronic inflammation. ${ }^{36}$ However, we cannot exclude that antiretroviral agents per se may induce in vivo platelet activation. ${ }^{37,38}$ Thus, analyzing the different antiretroviral treatment, we found that patients treated with protease inhibitors showed enhanced platelet oxidative stress and platelet activation compared to patients on non-nucleoside reverse transcriptase inhibitor-based regimens. This finding suggests that antiretroviral agents may have different impact on platelet function.

An implication of the study is that inhibition of NOX2 may represent a target to inhibit platelet activation in HIV1 patients. In this context, statins may be an interesting option as this drug category is able to down regulate 
NOX2. ${ }^{39}$ Small sample size is a limitation of the study, as it does not allow conclusive data on the role of HIV-1 and different antiretroviral agents on platelet function. In particular, we could not exclude that different impact of CART on platelet function and NOX activity might be mediated by modulation of platelet levels of cyclic AMP.

In conclusion, oxidative stress-mediated platelet activation may represent a mechanism potentially responsible for in vivo platelet activation in HIV-1 patients. Antiplatelet treatment including NOX inhibition, ${ }^{38}$ in addition to effective cART, may be an useful approach for the prevention of CV complications during HIV-1 infection.

\section{Conflict of interests}

None.

\section{Acknowledgments}

a) Acknowledgments: All authors have read and approved the final version of the paper.

All authors have substantially contributed to the study's conception, design, and performance.

b) Funding: the work was supported by an unrestricted Q2 educational grant from ViiV Healthcare.

c) Disclosures: None.

\section{References}

1. Antiretroviral Therapy Cohort Collaboration. Life expectancy of individuals on combination antiretroviral therapy in highincome countries: a collaborative analysis of 14 cohort studies. Lancet 2008 Jul 26;372(9635):293-9 [PubMed PMID: 18657708. Pubmed Central PMCID: 3130543].

2. Hsue PY, Lo JC, Franklin A, Bolger AF, Martin JN, Deeks SG, et al. Progression of atherosclerosis as assessed by carotid intima-media thickness in patients with HIV infection. Circulation 2004 Apr 6;109(13):1603-8 [PubMed PMID: 15023877].

3. Porter KM, Sutliff RL. HIV-1, reactive oxygen species, and vascular complications. Free Radic Biol Med 2012 Jul 1;53(1): 143-59 [PubMed PMID: 22564529. Pubmed Central PMCID: 3377788].

4. Zanni MV, Abbara S, Lo J, Wai B, Hark D, Marmarelis E, et al. Increased coronary atherosclerotic plaque vulnerability by coronary computed tomography angiography in HIV-infected men. Aids 2013 Jan 16 [PubMed PMID: 23324657].

5. Boccara F, Lang S, Meuleman C, Ederhy S, Mary-Krause M, Costagliola D, et al. HIV and coronary heart disease: time for a better understanding. J Am Coll Cardiol 2013 Feb 5;61(5): 511-23 [PubMed PMID: 23369416].

6. Vinikoor MJ, Napravnik S, Floris-Moore M, Wilson S, Huang DY, Eron JJ. Incidence and clinical features of cerebrovascular disease among HIV-infected adults in the Southeastern United States. AIDS Res Hum Retroviruses 2013 Jul;29(7):1068-74 [PubMed PMID: 23565888. Pubmed Central PMCID: 3685694].

7. Singer EJ, Valdes-Sueiras M, Commins DL, Yong W, Carlson M. HIV stroke risk: evidence and implications. Ther Adv Chronic Dis 2013 Mar;4(2):61-70 [PubMed PMID: 23556125. Pubmed Central PMCID: 3610259].

8. Freynhofer MK, Bruno V, Wojta J, Huber K. The role of platelets in athero-thrombotic events. Curr Pharm Des 2012;18(33): 5197-214 [PubMed PMID: 22724408].
9. Gresele P, Falcinelli E, Sebastiano M, Baldelli F. Endothelial and platelet function alterations in HIV-infected patients. Thromb Res 2012 Mar;129(3):301-8 [PubMed PMID: 22192157].

10. Pignatelli $P$, Carnevale $R$, Di Santo $S$, Bartimoccia $S$, Sanguigni V, Lenti L, et al. Inherited human gp91phox deficiency is associated with impaired isoprostane formation and platelet dysfunction. Arterioscler Thromb Vasc Biol 2011 Feb;31(2):423-34 [PubMed PMID: 21071703].

11. Griendling KK, Sorescu D, Ushio-Fukai M. NAD(P)H oxidase: role in cardiovascular biology and disease. Circ Res 2000 Mar 17; 86(5):494-501 [PubMed PMID: 10720409].

12. Pignatelli P, Carnevale R, Cangemi R, Loffredo L, Sanguigni V, Stefanutti $C$, et al. Atorvastatin inhibits gp91phox circulating levels in patients with hypercholesterolemia. Arterioscler Thromb Vasc Biol 2010 Feb;30(2):360-7 [PubMed PMID: 19965781].

13. Pignatelli $P$, Sanguigni $V$, Lenti L, Ferro D, Finocchi A, Rossi $P$, et al. gp91phox-dependent expression of platelet CD40 ligand. Circulation 2004 Sep 7;110(10):1326-9 [PubMed PMID: 15249506].

14. Carnevale R, luliano L, Nocella C, Bartimoccia S, Trape S, Russo R, et al. Relationship between platelet and urinary 8Iso-PGF2alpha levels in subjects with different degrees of NOX2 regulation. J Am Heart Assoc 2013;2(3):e000198 [PubMed PMID: 23770972].

15. Caccese D, Pratico D, Ghiselli A, Natoli S, Pignatelli P, Sanguigni $V$, et al. Superoxide anion and hydroxyl radical release by collagen-induced platelet aggregation - role of arachidonic acid metabolism. Thromb Haemost 2000 Mar; 83(3):485-90 [PubMed PMID: 10744158].

16. Freedman JE. CD40-CD40L and platelet function: beyond hemostasis. Circ Res 2003 May 16;92(9):944-6 [PubMed PMID: 12750303].

17. Antinori A, Marcotullio S, Ammassari A, Andreoni $M$, Angarano G, Armignacco 0 , et al. Italian guidelines for the use of antiretroviral agents and the diagnostic-clinical management of HIV-1 infected persons. Update 2011. New Microbiol 2012 Apr;35(2):113-59 [PubMed PMID: 22707127].

18. World Medical Association. World Medical Association Declaration of Helsinki. Ethical principles for medical research involving human subjects. Bull World Health Organ 2001; 79(4):373-4 [PubMed PMID: 11357217. Pubmed Central PMCID: 2566407].

19. Hoffman SW, Roof RL, Stein DG. A reliable and sensitive enzyme immunoassay method for measuring 8isoprostaglandin F2 alpha: a marker for lipid peroxidation after experimental brain injury. J Neurosci Methods 1996 Oct;68(2): 133-6 [PubMed PMID: 8912185].

20. Wang Z, Ciabattoni G, Creminon C, Lawson J, Fitzgerald GA, Patrono $C$, et al. Immunological characterization of urinary 8-epi-prostaglandin F2 alpha excretion in man. J Pharmacol Exp Ther 1995 Oct;275(1):94-100 [PubMed PMID: 7562601].

21. Fortuno A, Bidegain J, Robador PA, Hermida J, LopezSagaseta J, Beloqui O, et al. Losartan metabolite EXP3179 blocks NADPH oxidase-mediated superoxide production by inhibiting protein kinase $\mathrm{C}$ : potential clinical implications in hypertension. Hypertension 2009 Oct;54(4):744-50 [PubMed PMID: 19687351].

22. Carnevale R, Pignatelli P, Nocella C, Loffredo L, Pastori D, Vicario T, et al. Extra virgin olive oil blunt post-prandial oxidative stress via NOX2 down-regulation. Atherosclerosis 2014 Aug;235(2):649-58 [PubMed PMID: 24980290].

23. Torre D, Pugliese A. Platelets and HIV-1 infection: old and new aspects. Curr HIV Res 2008 Sep;6(5):411-8 [PubMed PMID: 18855651].

24. Flaujac C, Boukour S, Cramer-Borde E. Platelets and viruses: an ambivalent relationship. Cell Mol Life Sci - CMLS 2010 Feb;67(4):545-56 [PubMed PMID: 20012669]. 
25. Youssefian T, Drouin A, Masse JM, Guichard J, Cramer EM. Host defense role of platelets: engulfment of HIV and Staphylococcus aureus occurs in a specific subcellular compartment and is enhanced by platelet activation. Blood 2002 Jun 1; 99(11):4021-9 [PubMed PMID: 12010803].

26. Zucker-Franklin D, Seremetis S, Zheng ZY. Internalization of human immunodeficiency virus type I and other retroviruses by megakaryocytes and platelets. Blood 1990 May 15;75(10): 1920-3 [PubMed PMID: 2337668].

27. Francisci D, Falcinelli E, Belfiori B, Petito E, Guglielmini G, Malincarne $L$, et al. In vivo platelet activation and platelet hyperreactivity in abacavir-treated HIV-infected patients. Thromb Haemost 2013 May 23;110(2) [PubMed PMID: 23703656].

28. von Hentig N, Forster AK, Kuczka K, Klinkhardt U, Klauke S, Gute $P$, et al. Platelet-leucocyte adhesion markers before and after the initiation of antiretroviral therapy with HIV protease inhibitors. J Antimicrob Chemother 2008 Nov;62(5): 1118-21 [PubMed PMID: 18753189].

29. Song HY, Ju SM, Seo WY, Goh AR, Lee JK, Bae YS, et al. Nox2based NADPH oxidase mediates HIV-1 Tat-induced upregulation of VCAM-1/ICAM-1 and subsequent monocyte adhesion in human astrocytes. Free Radic Biol Med 2011 Mar 1; 50(5):576-84 [PubMed PMID: 21172429].

30. Pietraforte D, Tritarelli E, Testa U, Minetti M. gp120 HIV envelope glycoprotein increases the production of nitric oxide in human monocyte-derived macrophages. J Leukoc Biol 1994 Feb;55(2):175-82 [PubMed PMID: 8301214].

31. Olivetta E, Mallozzi C, Ruggieri V, Pietraforte D, Federico M, Sanchez M. HIV-1 Nef induces p47(phox) phosphorylation leading to a rapid superoxide anion release from the U937 human monoblastic cell line. J Cell Biochem 2009 Apr 1;106(5): 812-22 [PubMed PMID: 19130504].
32. Hulgan T, Morrow J, D'Aquila RT, Raffanti S, Morgan M, Rebeiro $\mathrm{P}$, et al. Oxidant stress is increased during treatment of human immunodeficiency virus infection. Clin Infect Dis Off Publ Infect Dis Soc Am 2003 Dec 15;37(12):1711-7 [PubMed PMID: 14689356].

33. Redhage LA, Shintani A, Haas DW, Emeagwali N, Markovic M, Oboho I, et al. Clinical factors associated with plasma F2isoprostane levels in HIV-infected adults. HIV Clin Trials 2009 May-Jun;10(3):181-92 [PubMed PMID: 19632957. Pubmed Central PMCID: 2891063].

34. Loffredo L, Carnevale R, Sanguigni V, Plebani A, Rossi P, Pignata $C$, et al. Does NADPH oxidase deficiency cause artery dilatation in humans? Antioxid Redox Signal 2013 Dec 7 [PubMed PMID: 23216310].

35. Morrow DA, Sabatine MS, Brennan ML, de Lemos JA, Murphy SA, Ruff CT, et al. Concurrent evaluation of novel cardiac biomarkers in acute coronary syndrome: myeloperoxidase and soluble CD40 ligand and the risk of recurrent ischaemic events in TACTICS-TIMI 18. Eur Heart J 2008 May;29(9):1096-102 [PubMed PMID: 18339606. Pubmed Central PMCID: 2829435].

36. Deeks SG. HIV infection, inflammation, immunosenescence, and aging. Annu Rev Med 2011;62:141-55 [PubMed PMID: 21090961. Pubmed Central PMCID: 3759035].

37. Violi F, Carnevale R, Pastori D, Pignatelli P. Antioxidant and antiplatelet effects of atorvastatin by Nox2 inhibition. Trends Cardiovasc Med 2013 Oct 2 [PubMed PMID: 24263084].

38. Violi F, Pignatelli P. Platelet NOX, a novel target for antithrombotic treatment. Thromb Haemost 2014 Jan 9;111(5) [PubMed PMID: 24402688].

39. Pignatelli P, Carnevale R, Pastori D, Cangemi R, Napoleone L, Bartimoccia S, et al. Immediate antioxidant and antiplatelet effect of atorvastatin via inhibition of Nox2. Circulation 2012 Jul 3;126(1):92-103 [PubMed PMID: 22615342]. 